\title{
POINT-PREVALENCE SURVEY ON DRUG SHORTAGE CHARACTERISTICS IN A DEVELOPING COUNTRY WITH A VERY SMALL PHARMACEUTICAL MARKET
}

\author{
NATASA DUBORIJA-KOVACEVIC ${ }^{1 *}$, JANA DJAPIC ${ }^{1}$, MIRJANA NEDOVIC-VUKOVIC ${ }^{2}$, \\ and ZELJKA BESOVIC ${ }^{3}$
}

\author{
${ }^{1}$ University of Montenegro, Medical Faculty, Department of Pharmacology and Clinical Pharmacology, \\ Podgorica, Montenegro \\ ${ }^{2}$ Institute for Public Health of Montenegro, Department of Medical Statistics and Informatics, \\ Podgorica, Montenegro \\ ${ }^{3}$ Montenegrin Institute for Medicines and Medical Devices, Podgorica, Montenegro
}

\begin{abstract}
The aim of this PPS was to investigate the characteristics of drug shortages (DS) in Montenegro and to identify possible specifics that could be related to the very small pharmaceutical market and lower financial expenditures for drugs in comparison with developed countries. PPS was conducted among hospital pharmacy (HP) and community pharmacy (CP) managers who reported DS. Statistical analyses were performed using IBM SPSS Statistics for Windows, Version 22.0. On the day of observation, there were 205 drugs in short supply and 391 reports of DS. The largest number of DS was related to ATC classes $\mathrm{N}(16.1 \%)$ and A (13.7\%). ATC class S (mainly ophthalmological) participated in DS with $12 \%$, although its share in total consumption was only $0.1 \%$. Almost two-thirds of missing drugs in CP (64\%) were solid formulations for oral use, but in HP injections/infusions were prevalent $(51 \%)(\mathrm{P}<0.001)$. Approximately $80 \%$ of deficient drugs in $\mathrm{HP}$ and $40 \%$ in $\mathrm{CP}$ were among reimbursed drugs $(\mathrm{P}<0.001)$. Slightly less than $50 \%$ of drugs in short supply were not registered. The majority of missing drugs were not essential (67\% in HP and 81\% in CP), mostly generics (>85\%). DS most often lasted over 90 days. Conclusion: Obtained results correspond to some extent to the findings from developed countries with larger pharmaceutical markets. However, certain specifics, which mainly relate to the regulatory status of deficient drugs, could be attributed to the influence of the small pharmaceutical market, as well as limited expenditures for drugs. The final conclusion requires more comprehensive analysis.
\end{abstract}

Keywords: drug shortages, characteristics, developing country, pharmaceutical market

Drug shortages (DS) are a complex and growing global challenge that affects health care systems regardless of the level of economic development (1-9).

A unique definition of DS does not yet exist (10). A recent WHO study identified more than fifty definitions (11) that coincide in some of their elements. According to Pauwels K et al., a DS can be defined 'as a shortcoming in the supply of a medicinal product that affects the patient's ability to access the required treatment in due time (12)." The causes of DS can be predictable and unpredictable (13), situated on both supply and demand sides (14). Finnish wholesalers and drug manufacturers considered the small size of the pharmaceutical market to be the most common cause of DS in that country (15).

DS affect all factors in the drug supply chain $(16,17)$. Patients are exposed to stress and anxiety, medication errors and adverse events, including deaths (3, 18-20). Additionally, DS increase their costs and reduce quality of life (21). Pharmacists usually identify the problem, look for an appropriate solution and apply it (22). As the consequence of workload during DS, they report medication errors such as drug omission, dispensing or administration of the wrong dose, or even of the wrong drug (23). Doctors must prioritize among patients due to the limited amount of medication, implement often risky therapeutic options and fit them into therapeutic protocols $(24,25)$. DS increase hospital, pharmacy, and staff costs, as well as a financial outlays of healthcare systems for more expensive therapeutic alternatives $(12,26)$. An important ethical and political dimension of DS cannot be ignored (4).

* Corresponding author: e-mail: duborijan@ucg.ac.me 
Data on DS characteristics vary widely in the available literature. According to the recent study (3), in less than a month 84 DS were registered in Canadian hospitals, 62 in French hospitals, 46 in Belgian hospitals, 28 in Spanish hospitals, and 98 in Swiss hospitals. In most cases, these were parenteral formulations, both innovative and generic. Antiinfectives for systemic use (ASU), drugs for the central nervous system (CNS), and cardiovascular system (CVS) were prevalent. The latest study from France covering the six-year period reported 3530 pharmaceutical products on shortage, including 1833 different active substances. Most often, these were old products with national marketing authorization procedures and approximately uniform participation of injectable and oral formulations (27). In this study, as in the previous one, it was shown that ASU, drugs for CNS and CVS were most often missing. According to Pauwels $\mathrm{K}$ et al. (28), the average duration of DS in seven developed European countries was 139 days. In approximately $50 \%$ of DS in Finnish community pharmacies (CP), a substitutable product was available (29).

European Medicines Agency (EMA) assesses DS that affect or are likely to affect more than one EU Member State (30). Most DS in the EU are dealt with at the national level and EMA provides a list of available online national registers of DS. However, not all EU countries, mainly small countries (i.e. Cyprus, Luxembourg, Malta, and Iceland), have available online DS registers (30). In the USA, Food and Drug Administration (FDA) created a searchable database (31) which is updated daily, with a focus on DS of medically necessary products with the greatest impact on public health.

High-income countries such as the USA, EU countries, Canada and Australia, as well as some middle-income countries, WHO, and many other international and national organizations and associations are making a great effort at different levels to effectively manage and mitigate DS (32). Shukar S et al. (32) recently systematized existing strategies managing DS in four groups: a) Management of current DS (restrictions and redistribution of available stock, use of products with minor defects and increase of expiry date, development of medical expert platforms for proactive handling of DS and wastage management), b) Improvement of operations (better communication among stakeholders, introduction of DS reporting and tracking systems, increase the number of manufacturers for generics, improved quality system and providing of multiple suppliers), c) Changes of governmental policy (establishing of various organizations to manage DS, advanced notification systems, adoption of national and international guidelines for DS mitigation, pricing policy modification and acceleration of the reviewing process) and d) Education and training of all staff involved in the drug supply chain, as well as public education and awareness through advertisements, campaigns, etc.

Having in mind Montenegrin demographic, socio-economic and regulatory specifics when it comes to turnover and utilization of drugs, we hypothesized that DS in our country differ at least in part from countries with larger pharmaceutical markets and with higher financial expenditures for drugs. The aim of this investigation was, for the first time in Montenegro, to analyze DS in terms of drug belonging to a certain pharmacotherapeutic class, its pharmaceutical formulation and regulatory/reimbursement status, duration, causes and substitution options. Obtained results were compared with available data from developed countries, and with larger populations in order to investigate the possible influence of a very small pharmaceutical market and limited financial expenditures for drugs on DS characteristics in Montenegro.

\section{METHODS}

\section{Background}

Montenegro is an old/new European and Mediterranean country with approximately 620000 inhabitants. It was a member of the common state of the Yugoslav peoples and in 2006 renewed its independence. Although precise data is missing, the general perception is that DS have been existed here for a few decades, at least since the nineties. It was a period of external economic sanctions, wars, and great migrations within the area of former Yugoslavia.

Montenegro has almost negligible domestic production of drugs (33) and relatively young regulatory institutions that register medicines according to the standards of the EU legislations in this area which are transposed to the national legislation in the process of joining the EU. Gross Domestic Product (GDP) per capita in 2017 was EUR 6908 and Healthcare system budget accounted for $4.6 \%$ of the country's $\operatorname{GDP}(34,35)$. Expenditures for drugs in 2016 were EUR 113.40 per capita (35) that was 3.7 times less than the EU average (36).

\section{Study design and sampling}

The data analyzed in this paper were obtained from the point-prevalence survey (PPS) which was conducted as the part of a two-year national research project entitled 'D Drug shortages in Montenegro as part of a complex global problem - dynamics, causes and possible solutions" (2018-2019), approved by the 
Ministry of Science of Montenegro (Decision No. 012696, 2017). Our project followed up on COST Action 15105 'European Medicines Shortages Research Network - addressing supply problems to patients" (2016-2021), in which Montenegro participates from the very beginning.

Participants in this survey were pharmacy managers who had previously signed an Informed consent. We assumed that, in the absence of an official national database of DS, they would be the most reliable source of data for this type of investigation. An invitation to participate was sent to all general and specialized HP in the country $(\mathrm{N}=13)$. Consent was received from 11, representing a response rate of $85 \%$. The sample of CP was formed after receiving information from the Pharmaceutical Chamber of Montenegro on which CP in each of the Montenegrin municipalities have the highest supply and annual turnover of medicines (excluding CP chains owned by the three largest wholesalers in the country). We invited $17 \mathrm{CP}$ managers to participate in the study, and $15(89 \%)$ accepted. In 11 cases, they were executives of the pharmacy chain, so the number of $\mathrm{CP}$ covered by the survey was 39 .

\section{Data collection and processing}

On Wednesday April 3, 2019, at 8 am, an email was sent to pharmacy managers. They were asked to report DS by filling out the table in attachment with drugs that were in short supply from the pharmacy/pharmacy chain on that day ((brand name, pharmaceutical formulation and strength, duration of shortage ( $<7$ days; 7-30 days; 30-90 days; $>90$ days or "I do not know"), substitution option (brand name, formulation, strength) and reason for DS)). The completed tables were sent back a day after by email or mail. Upon receiving the data, an Excel spreadsheet was created. Each brand name of the deficient drug was assigned an INN and ATC code (37). Registration/reimbursement and status of the drug on the WHO List of Essential Medicines were designated, based on the official documents of Montenegrin Institute for Medicines and Medical Devices (CInMED) (38), Health Insurance Fund of Montenegro (HIFM) (39), and WHO (40). Data on drug utilization in Montenegro in 2018 were obtained from the CInMED official annual report (41). Data on DS in other countries have been obtained from the relevant scientific literature and official online registers.

\section{Statistical analysis}

The statistical analyses were performed using IBM SPSS Statistics for Windows, Version 22.0. The
Chi-square test was used for categorical variables. Shapiro-Wilk test was used for testing the normality of variable distribution. The results are presented as the frequency for categorical variables and as means and standard deviations (SD) for normally distributed variables or medians and interquartile ranges for no normally distributed variables. Spearmen correlation coefficients (r) were calculated to evaluate correlations between the numbers of drugs/number of reports of drugs in short supply and drug utilization. A P value $<0.05$ was considered statistically significant.

\section{Ethics}

This research was approved by the Ethics Committee of the Medical faculty of the University of Montenegro (Decision No. 1113/3), on April 26, 2018.

\section{RESULTS}

\section{Drug shortages according to the ATC classification and correlation with drug utilization}

There were 205 drugs in short supply and 391 DS reports on the day of observation, of which approximately three quarters referred to CP (Table 1).

The distribution by ATC classes wasn't uniform $(\mathrm{P}<0.001)$ neither for the number of deficient drugs nor for the number of reports. The largest number of DS was related to ATC classes N (Nervous system) and A (Alimentary tract and metabolism), followed by C (Cardiovascular system) and S (Sensory organs). In ATC classes with higher utilization there was a larger number of drugs in short supply $(r=0.732$, $\mathrm{P}=0.002)$ and a larger number of reports of DS $(r=0.618, P=0.019)$. Some classes with an almost negligible share in total consumption (ATC classes S, D - Dermatologicals, and L - Antineoplastics and Immunomodulators) participated significantly more in DS.

The ten drugs with the highest number of reports of DS and the ten most used drugs in HP and $\mathrm{CP}$ in Montenegro (41) are presented in Table 2.

As regards HP, the only drug that belongs to the "Top 10" consumptions, as well as the 10 most reported DS, is the injectable anticoagulant enoxaparin. Oral antidiabetic metformin, NSAID diclofenac, and calcium antagonist amlodipine were in the top ten in terms of consumption as well as lacking in CP.

Methylergometrine, ketorolac, ibandronic acid, and chloropyramine were lacking in more than half of the HP that participated in this study. Pharmacists 
from more than half of $\mathrm{CP}$ reported a shortage of dorzolamide, potassium chloride, amlodipine, as many as seven drugs (metformin, diclofenac, clotrimazole, and hydroxychloroquine) (Table 2).

Table 1. The number of drugs short in supply, the number of reports of DS in one day in 2019, and drug utilization in Montenegro in 2018.

\begin{tabular}{|c|c|c|c|c|c|c|c|}
\hline \multirow{2}{*}{$\begin{array}{l}\text { ATC class } \\
\left(1^{\text {st }} \text { level }\right)\end{array}$} & \multicolumn{3}{|c|}{$\begin{array}{l}\text { Number of drugs in short supply } \\
\text { in one day in } 2019\end{array}$} & \multicolumn{3}{|c|}{$\begin{array}{l}\text { Number of reports of drug shortages } \\
\text { in one day in } 2019\end{array}$} & \multirow{2}{*}{$\begin{array}{l}\text { Drug utilization } \\
\text { in } 2018 \\
\text { DDD/1000/day } \\
(\%)^{(41)}\end{array}$} \\
\hline & \begin{tabular}{|c|}
$\begin{array}{c}\text { Community } \\
\text { pharmacies } \\
\mathrm{N}(\%)\end{array}$ \\
\end{tabular} & \begin{tabular}{|c|} 
Hospital \\
pharmacies \\
$\mathrm{N}(\%)$
\end{tabular} & $\begin{array}{l}\text { Total } \\
\text { N (\%) }\end{array}$ & \begin{tabular}{|c|} 
Community \\
pharmacies \\
$\mathrm{N}(\%)$
\end{tabular} & $\begin{array}{c}\text { Hospital } \\
\text { pharmacies } \\
\mathrm{N}(\%)\end{array}$ & $\begin{array}{l}\text { Total } \\
\mathrm{N}(\%)\end{array}$ & \\
\hline $\begin{array}{l}\text { Alimentary tract } \\
\text { and metabolism } \\
\text { (A) }\end{array}$ & $\begin{array}{c}19 \\
(12.7 \%)\end{array}$ & $\begin{array}{c}9 \\
(16.4 \%)\end{array}$ & $\begin{array}{c}28 \\
(13.7 \%)\end{array}$ & $\begin{array}{c}49 \\
(15.9 \%)\end{array}$ & $\begin{array}{c}11 \\
(13.2 \%)\end{array}$ & $\begin{array}{c}60 \\
(15.3 \%)\end{array}$ & $\begin{array}{c}128.5 \\
(10.6 \%)\end{array}$ \\
\hline $\begin{array}{c}\text { Cardiovascular system } \\
\text { (C) }\end{array}$ & $\begin{array}{c}20 \\
(13.3 \%) \\
\end{array}$ & $\begin{array}{c}3 \\
(5.4 \%) \\
\end{array}$ & $\begin{array}{c}23 \\
(11.2 \%)\end{array}$ & $\begin{array}{c}33 \\
(10.7 \%) \\
\end{array}$ & $\begin{array}{c}5 \\
(6.0 \%) \\
\end{array}$ & $\begin{array}{c}38 \\
(9.7 \%) \\
\end{array}$ & $\begin{array}{c}413.2 \\
(34.1 \%)\end{array}$ \\
\hline $\begin{array}{l}\text { Dermatologicals } \\
\text { (D) }\end{array}$ & $\begin{array}{c}5 \\
(3.3 \%) \\
\end{array}$ & $\begin{array}{c}3 \\
(5.4 \%) \\
\end{array}$ & $\begin{array}{c}8 \\
(3.9 \%) \\
\end{array}$ & $\begin{array}{c}7 \\
(2.3 \%) \\
\end{array}$ & $\begin{array}{c}3 \\
(3.6 \%)\end{array}$ & $\begin{array}{c}10 \\
(2.6 \%)\end{array}$ & $\begin{array}{c}0.2 \\
(0.0 \%)\end{array}$ \\
\hline $\begin{array}{l}\text { Anti-infectives for } \\
\text { systemic use } \\
(\mathrm{J})\end{array}$ & $\begin{array}{c}15 \\
(10.0 \%)\end{array}$ & $\begin{array}{c}4 \\
(7.3 \%)\end{array}$ & $\begin{array}{c}19 \\
(9.3 \%)\end{array}$ & $\begin{array}{c}19 \\
(6.2 \%)\end{array}$ & $\begin{array}{c}6 \\
(7.2 \%)\end{array}$ & $\begin{array}{c}25 \\
(6.4 \%)\end{array}$ & $\begin{array}{c}27.2 \\
(2.2 \%)\end{array}$ \\
\hline $\begin{array}{l}\text { Antineoplastics and } \\
\text { immunomodulators } \\
\text { (L) }\end{array}$ & $\begin{array}{c}1 \\
(0.7 \%)\end{array}$ & $\begin{array}{c}4 \\
(7.3 \%)\end{array}$ & $\begin{array}{c}5 \\
(2.4 \%)\end{array}$ & $\begin{array}{c}1 \\
(0.3 \%)\end{array}$ & $\begin{array}{c}4 \\
(4.8 \%)\end{array}$ & $\begin{array}{c}5 \\
(1.3 \%)\end{array}$ & $\begin{array}{c}6.2 \\
(0.5 \%)\end{array}$ \\
\hline $\begin{array}{c}\text { Musculo-sceletal } \\
\text { system } \\
\text { (M) }\end{array}$ & $\begin{array}{c}12 \\
(8.0 \%)\end{array}$ & $\begin{array}{c}4 \\
(7.3 \%)\end{array}$ & $\begin{array}{c}16 \\
(7.8 \%)\end{array}$ & $\begin{array}{c}28 \\
(9.1 \%)\end{array}$ & $\begin{array}{c}12 \\
(14.5 \%)\end{array}$ & $\begin{array}{c}40 \\
(10.2 \%)\end{array}$ & $\begin{array}{c}79.3 \\
(6.5 \%)\end{array}$ \\
\hline $\begin{array}{l}\text { Nervous system } \\
(\mathrm{N})\end{array}$ & $\begin{array}{c}25 \\
(16.7 \%) \\
\end{array}$ & $\begin{array}{c}8 \\
(14.5 \%) \\
\end{array}$ & $\begin{array}{c}33 \\
(16.1 \%) \\
\end{array}$ & $\begin{array}{c}43 \\
(14.0 \%) \\
\end{array}$ & $\begin{array}{c}9 \\
(10.8 \%) \\
\end{array}$ & $\begin{array}{c}52 \\
(13.3 \%) \\
\end{array}$ & $\begin{array}{c}117.6 \\
(9.7 \%)\end{array}$ \\
\hline $\begin{array}{l}\text { Respiratory tract } \\
\text { (R) }\end{array}$ & $\begin{array}{c}15 \\
(10.0 \%)\end{array}$ & $\begin{array}{c}3 \\
(5.4 \%) \\
\end{array}$ & $\begin{array}{c}18 \\
(8.8 \%)\end{array}$ & $\begin{array}{c}30 \\
(9.7 \%)\end{array}$ & $\begin{array}{c}7 \\
(8.4 \%) \\
\end{array}$ & $\begin{array}{c}37 \\
(9.5 \%)\end{array}$ & $\begin{array}{c}69.2 \\
(5.7 \%)\end{array}$ \\
\hline $\begin{array}{l}\text { Sensory organs } \\
\text { (S) }\end{array}$ & $\begin{array}{c}19 \\
(12.7 \%)\end{array}$ & $\begin{array}{c}4 \\
(7.3 \%)\end{array}$ & $\begin{array}{c}23 \\
(11.2 \%) \\
\end{array}$ & $\begin{array}{c}51 \\
(16.5 \%) \\
\end{array}$ & $\begin{array}{c}4 \\
(4.8 \%)\end{array}$ & $\begin{array}{c}55 \\
(14.1 \%) \\
\end{array}$ & $\begin{array}{c}1.3 \\
(0.1 \%)\end{array}$ \\
\hline $\begin{array}{c}\text { Others } \\
(\mathrm{B}, \mathrm{G}, \mathrm{H}, \mathrm{P}, \mathrm{V})\end{array}$ & $\begin{array}{c}19 \\
(12.6 \%) \\
\end{array}$ & $\begin{array}{c}13 \\
(23.7 \%) \\
\end{array}$ & $\begin{array}{c}32 \\
(15.7 \%) \\
\end{array}$ & $\begin{array}{c}47 \\
(15.3 \%) \\
\end{array}$ & $\begin{array}{c}22 \\
(26.4 \%) \\
\end{array}$ & $\begin{array}{c}69 \\
(17.6 \%) \\
\end{array}$ & $\begin{array}{c}370.4 \\
(30.5 \%) \\
\end{array}$ \\
\hline Total & $\begin{array}{c}150 \\
(100 \%) \\
\end{array}$ & $\begin{array}{c}55 \\
(100 \%) \\
\end{array}$ & $\begin{array}{c}205 \\
(100 \%) \\
\end{array}$ & $\begin{array}{c}308 \\
(100 \%) \\
\end{array}$ & $\begin{array}{c}83 \\
(100 \%) \\
\end{array}$ & $\begin{array}{c}391 \\
(100 \%) \\
\end{array}$ & $\begin{array}{c}1213.1 \\
(100.0 \%) \\
\end{array}$ \\
\hline
\end{tabular}

Table 2. The ten most reported drug shortages and the ten most used drugs in Montenegro by generic name.

\begin{tabular}{|c|c|c|c|c|}
\hline \multirow{2}{*}{$\begin{array}{c}\text { Ord. } \\
N^{\circ}\end{array}$} & \multicolumn{2}{|c|}{ Hospital pharmacies } & \multicolumn{2}{c|}{ Community pharmacies } \\
\cline { 2 - 5 } & Shortages 2019 & Utilization $2018^{(41)}$ & Shortages 2019 & Utilization $2018^{(41)}$ \\
\hline 1. & Methylergometrine* & Hydroxicobalamin & Metformin* & Folic acid \\
\hline 2. & Ketorolac* & Folic acid & Diclofenac* & Acetylsalicylic acid \\
\hline 3. & Ibandronic acid* & Enoxaparin** & Dorzolamide* & Ramipril \\
\hline 4. & Chloropyramine* & Methylprednisolone & Potassium chloride* & Hydroxocobalamin \\
\hline 5. & Potassium chloride & Dexamethasone & Amlodipine* & Diclofenac** \\
\hline 6. & Bisacodyl & Pantoprazole & Clotrimazole* & Amlodipine** \\
\hline 7. & Askorbic acid & Diazepam & Hydroxychloroquine* & Fosinopril, HCT \\
\hline 8. & Enoxaparin & Ceftriaxone & Levothyroxine & Fosinopril \\
\hline 9. & Furosemide & Metamizole & Clonazepam & Metformin** \\
\hline 10. & Ciprofloxacin & Ranitidine & Doxepin & Lisinopril, HCT \\
\hline
\end{tabular}

* Over $50 \%$ of participants reported shortage

** The drug is found in the 10 most reported shortages in HP / CP pharmacies 


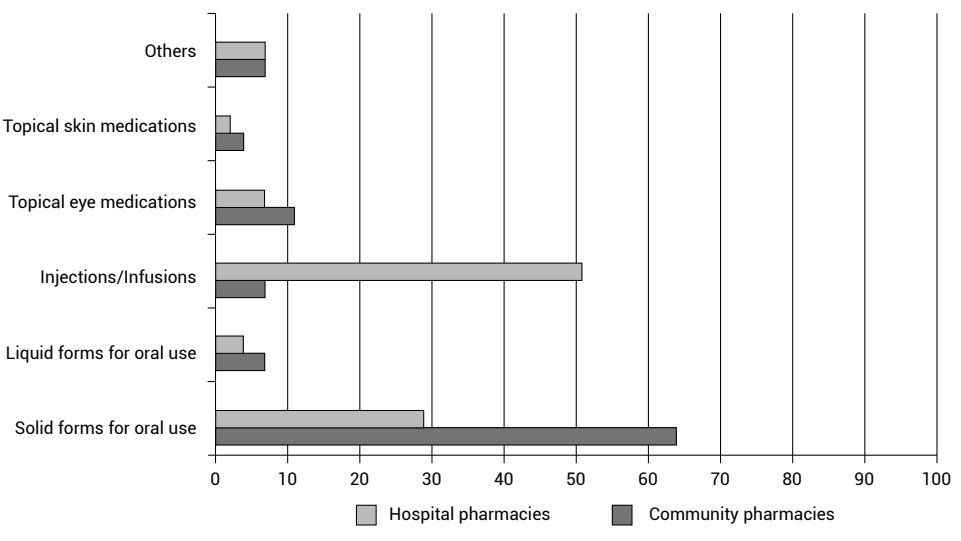

Figure 1. DS in community and hospital pharmacies in Montenegro in one day in 2019, according to pharmaceutical formulation, in percentages (\%).

\section{Drug shortages according to pharmaceutical formulation}

Overall, Montenegrin pharmacies most often lacked oral formulations. They were most often in short supply in CP, but injections/infusions were prevalent in HP $(\mathrm{P}<0.001)$ (Fig. 1).

\section{Drug shortages according to registration/reimbursement status and status on the WHO List of Essential Medicines}

Slightly more than $50 \%$ of all drugs in short supply weren't reimbursed by the HIFM (Table 3). The number of reimbursed drugs in short supply was significantly higher in HP than in $\mathrm{CP}(\mathrm{P}<0.001)$. A little over half of the missing drugs were registered in CInMED, without difference between HP and CP.
A significant majority of deficient drugs were not essential $(\mathrm{P}=0.043)$. Almost all drugs in short supply in HP were generics (93\%), while this percentage was slightly lower in $\mathrm{CP}(\mathrm{P}=0.159)$.

\section{Duration of drug shortages, causes, and substitution options}

In both HP and CP, DS most often lasted over 90 days, but in $\mathrm{CP}$ significantly longer $(\mathrm{P}=0.024)$ (Table 4).

The longest DS in HP were among ATC classes A, N, and R (Respiratory tract), and the shortest in ATC classes J (Anti-infectives for systemic use), B (Blood and blood-forming organs), and L (Antineoplastics and immunomodulators). In CP, the longest DS were reported in classes R, S, and N. DS shorter than seven days were rarely reported.

Table 3. DS in Montenegro in one day in 2019, according to registration/reimbursement status and status on the WHO Essential Medicines List.

\begin{tabular}{|c|c|c|c|c|c|c|}
\hline \multicolumn{2}{|c|}{$\begin{array}{c}\text { Registration / reimbursement status of drugs in short } \\
\text { supply and status on the WHO Essential Medicines } \\
\text { List }\end{array}$} & \multirow{2}{*}{$\begin{array}{c}\text { Hospital } \\
\text { pharmacies } \\
\mathrm{N}(\%)\end{array}$} & \multirow{2}{*}{ 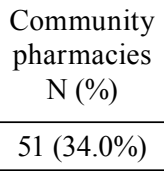 } & \multirow{2}{*}{$\begin{array}{c}\text { Total } \\
\text { N }(\%) \\
93(45.4 \%)\end{array}$} & $\chi^{2}$ & $\mathrm{p}$ \\
\hline \multirow{4}{*}{$\begin{array}{l}\text { Reimbursement by } \\
\text { HIFM }^{* *}\end{array}$} & Basic list* & & & & \multirow{4}{*}{26.006} & \multirow{4}{*}{$<0.001$} \\
\hline & Supplementary list* & $0(0.0 \%)$ & $6(4.0 \%)$ & $6(2.9 \%)$ & & \\
\hline & $\begin{array}{l}\text { List of drugs with special } \\
\text { regimen of dispensing* }\end{array}$ & $1(1.8 \%)$ & $0(0.0 \%)$ & $1(0.5 \%)$ & & \\
\hline & Not on the list & $12(21.8 \%)$ & $93(62.0 \%)$ & $105(51.2 \%)$ & & \\
\hline \multirow{2}{*}{$\begin{array}{l}\text { Registration by } \\
\text { CInMED }\end{array}$} & Registered & $30(54.6 \%)$ & $80(53.3 \%)$ & $110(53.7 \%)$ & \multirow{2}{*}{0.024} & \multirow{2}{*}{0.877} \\
\hline & Not registered & $25(45.4 \%)$ & $70(46.7 \%)$ & $95(46.3 \%)$ & & \\
\hline \multirow{3}{*}{$\begin{array}{l}\text { WHO List of Essential } \\
\text { Medicines }^{(40)}\end{array}$} & Core list & $15(27.3 \%)$ & $25(16.7 \%)$ & $40(19.5 \%)$ & \multirow{3}{*}{4.086} & \multirow{3}{*}{0.043} \\
\hline & Complementary list & $3(5.4 \%)$ & $4(2.7 \%)$ & $7(3.4 \%)$ & & \\
\hline & Not on the list & $37(67.3 \%)$ & $121(80.7 \%)$ & $158(77.1 \%)$ & & \\
\hline \multirow{2}{*}{$\begin{array}{l}\text { Originator/ } \\
\text { generic }\end{array}$} & Originator & $4(7.3 \%)$ & $22(14.7 \%)$ & $26(12.7 \%)$ & \multirow{2}{*}{1.987} & \multirow{2}{*}{0.159} \\
\hline & Generic & $51(92.7 \%)$ & $128(85.3 \%)$ & $179(87.3 \%)$ & & \\
\hline
\end{tabular}

* If the drug is on the list, it means that it is fully or partially reimbursed by HIFM.

** Health Insurance Fund of Montenegro

*** Montenegrin Institute for Medicines and Medical Devices 
Table 4. Duration of DS in Montenegrin pharmacies, causes, and substitution options.

\begin{tabular}{|c|c|c|c|c|}
\hline \multicolumn{2}{|c|}{$\begin{array}{c}\text { Duration, causes, } \\
\text { and substitution options }\end{array}$} & $\begin{array}{c}\text { Hospital pharmacies } \\
\text { N (\%) }\end{array}$ & $\begin{array}{c}\text { Community pharmacies } \\
\text { N (\%) }\end{array}$ & $\begin{array}{c}\text { Total } \\
\text { N (\%) }\end{array}$ \\
\hline \multirow{4}{*}{ Duration } & $<7$ days & $5(6.0 \%)$ & $9(3.0 \%)$ & $14(3.6 \%)$ \\
\cline { 2 - 5 } & $7-30$ days & $20(24.1 \%)$ & $78(25.3 \%)$ & $98(25.1 \%)$ \\
\cline { 2 - 5 } & $30-90$ days & $16(19.3 \%)$ & $110(35.7 \%)$ & $126(32.2 \%)$ \\
\cline { 2 - 5 } & $>90$ days & $39(47.0 \%)$ & $111(36.0 \%)$ & $150(38.4 \%)$ \\
\hline \multirow{5}{*}{ Cause } & Unknown & $3(3.6 \%)$ & $0(0.0 \%)$ & $3(0.8 \%)$ \\
\cline { 2 - 5 } & Unknown & $20(24.1 \%)$ & $109(35.4 \%)$ & $129(33.0 \%)$ \\
\cline { 2 - 5 } & Known & $57(68.7 \%)$ & $92(29.9 \%)$ & $149(38.1 \%)$ \\
\cline { 2 - 5 } & No answer & $6(7.2 \%)$ & $107(34.7 \%)$ & $113(28.9 \%)$ \\
\hline \multirow{5}{*}{ Substitution } & Generic & $4(4.8 \%)$ & $77(25 \%)$ & $81(20.7 \%)$ \\
\cline { 2 - 5 } & Therapeutic & $6(7.2 \%)$ & $21(6.8 \%)$ & $27(6.9 \%)$ \\
\cline { 2 - 5 } & No & $31(37.3 \%)$ & $90(29.2 \%)$ & $121(30.9 \%)$ \\
\cline { 2 - 5 } & No answer & $42(50.6 \%)$ & $120(39.0 \%)$ & $162(41.4 \%)$ \\
\hline
\end{tabular}

About $38 \%$ of pharmacy managers were aware of the causes of DS, with a significantly higher percentage in the group of HP managers $(\mathrm{P}<0.001)$ (Table 4).

Approximately one-third of missing drugs did not have a substitution. In cases where there was a substitution, generic was three times more common than therapeutic. CP had a significantly higher percentage of substitution than HP (31.8\% vs. $12 \%$, $\mathrm{P}=0.002)$. In HP, patients received a therapeutic substitution more often, and in $\mathrm{CP}$ a generic one $(\mathrm{P}=0.001)$.

\section{DISCUSSION AND CONCLUSION}

Considering the participation of major ATC classes, formulations, and essential drugs in DS, as well as their duration, it can be stated that the characteristics of DS in Montenegro don't differ significantly from available data from developed countries with greater pharmaceutical markets. However, our hypothesis can be accepted because some specifics that could be attributed to the impact of a very small pharmaceutical market and/or significantly lower financial allocations for drugs were found. This primarily refers to the large participation of unregistered, non-refunded drugs and generics in DS, as well as the prevalence of DS in some ATC classes with low utilization.

On the day of the observation, 205 drugs were in short supply, of which approximately three quarters referred to CP. The obtained result is mostly a consequence of a greater share of outpatient spending in total drug utilization $(41,42)$. A similar PPS conducted in Australia in 2017 reported 365 drugs in short supply in HP in just one day (43). A positive correlation between DS and drug consumption is in line with published research according to which DS most often occur in ATC classes of highest consumption $(3,26,27,29)$. Drugs for diseases of the sensory organs (mainly ophthalmological) participated in DS with $12 \%$, although they participated in total consumption with only $0.1 \%$ (41). In this case, as in the case of some other low-consumption classes (dermatologicals, antineoplastics, etc.), the impact of a small pharmaceutical market on DS cannot be ruled out. More specifically, pharmaceutical companies probably have the least interest in registering and marketing drugs with the lowest consumption in the small pharmaceutical markets. Dutch pharmacists have also detected ophthalmologicals among the most commonly in short supply in 2012-2015 (44).

Enoxaparin was the only drug in short supply in HP that was also in the top ten drugs in terms of consumption and in CP these were diclofenac, amlodipine, and metformin (41). Shortages of the last three drugs were reported by more than $50 \%$ of CP. None of the ten most reported DS that were identified both in HP and CP in this PPS (Table 2) are listed in the EMA shortages catalog (30), but certain similarities have been found when it comes to some EU countries. For example, none of the INN from the ten most reported DS in HP in Montenegro was registered in Croatian database of DS in 2019 and only one INN (metformin) from CP was also recorded as DS in the Croatia (45). In Slovenia, 2 INN from the CP top ten DS were also reported in 2019 (clotrimazole and levothyroxine) and 4 INN from the HP list (ketorolac, methylergometrine, furosemide, and ciprofloxacin) (46). Three INN from the CP top ten DS (metformin, 
diclofenac, and clotrimazole) and 2 INN from the HP list (ibandronic acid and furosemide) were reported in the Czech Republic in 2019 (47).

Apart from diclofenac, other missing drugs from the top 10 used are essential drugs (40) with high utilization (41), so their deficiency could disrupt the treatment of many patients or leave them without access to treatment. However, for some missing drugs there was an appropriate reimbursed therapeutic parallel (nadroparin instead of enoxaparin), for some of them there was generic parallel from other manufacturers (metformin), for some of them there was both generic and therapeutic parallel (ibandronic acid), but some of them (amlodipine) had neither a generic nor a therapeutic parallel among the calcium-channel blockers being refunded (39). In this and similar cases, physicians chose the optimal option among other available classes of drugs, about which pharmacists were probably not informed. This is best illustrated by the result of this PPS according to which about $50 \%$ of hospital pharmacists did not know whether there was a substitute for the missing drug or not.

The results on shares of certain pharmaceutical formulations in DS were expected, as well as a difference between HP and CP. Possible explanations could be the type and severity of inpatient clinical conditions and (im)possibility of oral administration of drugs, the need for faster response in hospitals, etc. The same order, but different participation of individual pharmaceutical formulations was found in developed European countries (28).

In total, the representation of medicines in short supply that were reimbursed by HIFM and those who were not was almost equal. At the same time, the participation of reimbursed drugs in short supply was significantly higher in HP than in CP. At least two explanations for this result are possible. The first is that OTC drugs that are not refundable had a large share in DS (primarily in CP), and the second is that these were often more expensive drugs, which, according to the existing rules, have a worse position in comparison to cheaper generics when forming a Positive list. Only registered brands may be on the lists of refundable drugs, which could also affect the obtained result.

Approximately $50 \%$ of medicines in short supply were not registered at the time of this research. We did not find a similar result in the available literature from developed countries. Possible explanations could be a relatively little interest from pharmaceutical companies in registering drugs because of a very small market and/or the absence of certain drugs from the Positive list, due to limited expenditures for drugs. In some cases of DS, these were old, generic drugs, exceeded with newer therapeutic options, with which some doctors, but also patients (OTC drugs) are still not familiar. Bankruptcy and/or cessation of production in the case of some regional manufacturers, on which domestic wholesalers relied significantly for years, reflected in the emergence of DS, too.

One-fifth of the drugs in short supply in Montenegrin pharmacies was essential, which would most likely mean that the majority of patients were not at risk due to lack of medication. A similar percent was found in developed European countries (28).

The relatively large participation of generics was expected, given their share in the lists of reimbursed drugs. The participation of branded drugs in DS in developed European countries is significantly higher (28). A possible explanation of our result could be the absence of own medicine production and the need to import cheaper generic drugs, lower financial allocations for drugs compared to developed countries (35), weaker motivation of manufacturers of (expensive) originators to register drugs on the small market, current principles of making a Positive list, by which cheaper generic drugs are favored, etc. In any case, this result could be affirmative from the pharmacoeconomic point of view.

About $38 \%$ of Montenegrin pharmacy managers were aware of the causes of DS. Almost identical result (36\%) was obtained in developed European countries (28). Studies from Canada and Finland reported lower percentages compared to ours $(3,29)$. Tender procurement of medicines for HP is most likely the decisive reason for the significant difference between HP and CP when it comes to the possibility of replacing drugs in short supply. In the absence of generic substitution, hospital doctors were probably forced to prescribe a more or less appropriate therapeutic parallel previously procured through tender, while CP were better supplied with generic parallels, especially in the case of OTC drugs.

When it comes to the duration of DS, our results are in line with results from developed European countries (28). A longer duration of DS in CP compared to HP could be primarily explained by different clinical characteristics of inpatient and outpatient drug use.

Some limitations of this study were identified. In the absence of an official database on DS, the data were obtained from the pharmacy managers, so the influence of a subjective factor cannot be ruled out. With this type of survey, we were deprived of clinical, humanistic, and economic implications of DS. Monitoring of DS was carried out in just one day and on a relatively small sample when it comes to 
$\mathrm{CP}$, although their duration, as well as the response rate of participants, reduces the negative impact of this restriction to some extent.

Results on DS characteristics in Montenegro correspond to some extent to the findings published from developed countries with larger pharmaceutical markets. In that sense, it could be inferred that the size of the Montenegrin pharmaceutical market and allocated financial expenditures for drugs do not decisively affect the characteristics of DS. However, our hypothesis can be accepted because certain specifics, which mainly relate to the regulatory status of deficient drugs, could be attributed to the influence of these factors. In order to reach a final conclusion, more comprehensive analyses are needed.

\section{Conflict of interest}

The authors declare no conflicts of interest.

\section{REFERENCES}

1. Gray A., Manasse H.R.: Bull. World Health Organ. 90, 158 (2012).

2. Said A., Goebel R., Ganso M., ZagermannMuncke P., Schulz M.: Health Policy 122, 1302 (2018).

3. Videau M., Chemali L., Stucki C., SaavedraMitjans M., Largana S., et al.: Can. J. Hosp. Pharm. 72, 7 (2019).

4. Bochenek T., Abilova V., Alkan A., Asanin B., de Miguel Beriain I., et al.: Front. Pharmacol. 8, 942 (2018).

5. Nonzee N.J., Luu T.H.: Cancer Treat. Res. 171, 75 (2019).

6. Ventola C.L.: P.T. 36, 412 (2011).

7. Kohl S.: Eur. J. Hosp. Pharm. 25, 173 (2018).

8. Miljković N., Godman B., Kovačević M., Polidori P., Tzimis L., et al.: Front. Pharmacol. 11, 357 (2020).

9. Barlas S.: P.T. 38, 261 (2013).

10. De Weerdt E., Simoens S., Casteels M., Huys I.: Front. Pharmacol. 6, 253 (2015).

11. World Health Organization, Meeting report: Technical Definitions of Shortages and Stockouts of Medicines and Vaccines, WHO, Geneva 2016.

12. Pauwels K., Simoens S., Casteels M., Huys I.: PLoS One 10, e0119322 (2015).

13. Birgli ${ }^{\circledR}$ ag, An Evaluation of Medicines Shortages in Europe with a more in-depth review of these in France, Greece, Poland, Spain, and the United Kingdom, Zug 2013.

14. Musazzi U.M., Di Giorgio D., Minghetti P.: Int. J. Pharm. 579, 47 pages (2020).
15. Heiskanen K., Ahonen R., Kanerva R., Karttunen P., Timonen J.: PLoS One 12, e0179479 (2017).

16. Yang C., Wu L., Cai W., Zhu W., Shen Q., Li Z., et al.: PLoS One 11, e0165183 (2016).

17. Bogaert P., Bochenek T., Prokop A., Pilc A.: PLoS One 10, e0125691 (2015).

18. Rinaldi F., de Denus S., Nguyen A., Nattel S., Bussieres J.F.: Can. J. Cardiol. 33, 283 (2017).

19. Gatesman M.L., Smith T.J.: N. Engl. J. Med. 365, 1653 (2011).

20. Fox E.R., Sweet B.V., Jensen V.: Mayo Clin. Proc. 89, 361 (2014).

21. Phuong J.M., Penm J., Chaar B., Oldfield L.D., Moles R.: PLoS One 14, e0215837 (2019).

22. Claus B., Pauwels K., Baert M., Depoorter J., De Weerdt E., et al.: J. Pharm. Belg. 1, 24 (2015).

23. McLaughlin M., Kotis D., Thomson K., Harrison M., Fennessy G., et al.: J. Manag. Care Pharm. 19, 783 (2013).

24. Yang C., Cai W., Li Z., Page A.T., Fang Y.: PLoS One 13, e0205238 (2018).

25. Banerjee R., Thurm C.W., Fox E.R., Hersh A.L.: Pediatrics 142, e20180858 (2018).

26. Schwartzberg E., Ainbinder D., Vishkauzan A., Gamzu R.: Isr. J. Health Policy Res. 6, 17 (2017).

27. Benhabib A., Ioughlissen S., RatignierCarbonneil C., Maison P.: BMJ Open 10, E034033 (2020).

28. Pauwels K., Huys I., Casteels M., Simoens S.: BMC Health Serv. Res. 14, 438 (2014).

29. Heiskanen K., Ahonen R., Karttunen P., Kanerva R., Timonen J.: Health Policy 119, 232 (2015).

30. https://www.ema.europa.eu/en/humanregulatory/post-authorisation/availabilitymedicines/shortages-catalogue, (accessed on August, 2021).

31. https://www.accessdata.fda.gov/scripts/ drugshortages/dsp_faq.cfm, (accessed on

August, 2021).

32. Shukar S., Zahoor F., Hayat K., Saeed A., Gillani A.H., et al.: Front. Pharmacol. 12, 693426 (2021).

33. Imasheva A., Seiter A.: The Pharmaceutical Sector of the Western Balkan Countries, The International Bank for Reconstruction and Development / The World Bank, Washington 2008.

34. Montenegro Statistical Office, Statistical Yearbook, MONSTAT, Podgorica 2018.

35. Government of Montenegro, Ministry of Health of Montenegro, Health Care System 2017-2018, Podgorica 2018.

36. OECD/European Union, Pharmaceutical expenditure, In: Health at a Glance: Europe 
2018: State of Health in the EU Cycle. OECD Publishing, Paris/European Union, Brussels.

37. WHO Collaborating Centre for Drug Statistics Methodology, ATC/DDD Index 2021, Norwegian Institute for Public Health, Oslo 2020.

38. Agency for Medicines and Medical Devices of Montenegro, Register of Medicines for human use, Podgorica 2019.

39. Health Insurance Fund of Montenegro, List of medicines 2019, Podgorica 2019.

40. World Health Organization, Model List of Essential Medicines, 21st List, WHO, Geneva 2019.

41. Agency for Medicines and Medical Devices of Montenegro, Report on the consumption of drugs for human use in Montenegro for 2018, CALIMS, Podgorica 2019.

42. Sabate M., Ferrer P., Ballarin E., Rottenkolber M., Amelio J., Schmiedl S., et al., on behalf of PROTECT Work Package 2.: Bas. Clin. Pharmacol. Toxicol. 116, 201 (2015).

43. The Society of Hospital Pharmacists of Australia, Medicine shortages in Australia. A snapshot of shortages in Australian hospitals, SHPA, June 2017.

44. Postma D.J., De Smet P.A.G., Gispen-de Wied C.C., Leufkens H.G.M., Mantel-Teeuwisse A.K.: Front. Pharmacol. 9, 1243 (2018).

45. https://www.halmed.hr/en/Promet-proizvodnjai-inspekcija/Promet/Prekid-opskrbe-trzistalijekom-i-nestasice/, (accessed on August, 2021).

46. https://www.jazmp.si/humana-zdravila/podatkio-zdravilih/zdravila-na-trgu/, (accessed on August, 2021).

47. https://prehledy.sukl.cz/mr.html\#/, (accessed on August, 2021).

(C) 2021 by Polish Pharmaceutical Society. This is an open-access article under the CC BY NC license (https://creativecommons.org/licenses/by-nc/4.0/). 